\title{
The caspase-generated fragments of PKR cooperate to activate full-length PKR and inhibit translation
}

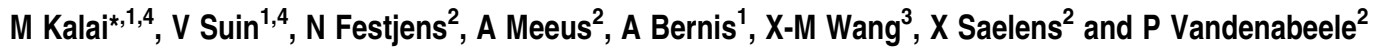

We have studied the involvement of receptor interacting protein kinase-1 (RIP1) and dsRNA-activated protein kinase (PKR) in external dsRNA-induced apoptotic and necrotic cell death in Jurkat T cell lymphoma. Our results suggest that RIP1 plays an imported role in dsRNA-induced apoptosis and necrosis. We demonstrated that contrary to necrosis, protein synthesis is inhibited in apoptosis. Here, we show that phosphorylation of translation initiation factor $2-\alpha$ (eukaryotic initiation factor $2-\alpha$ (elF2- $\alpha$ )) and its kinase, PKR, occur in dsRNA-induced apoptosis but not in necrosis. These events are caspase-dependent and coincide with the appearance of the caspase-mediated PKR fragments, N-terminal domain (ND) and kinase domain (KD). Our immunoprecipitation experiments demonstrated that both fragments could independently co-precipitate with full-length PKR. Expression of PKR-KD leads to PKR and elF2- $\alpha$ phosphorylation and inhibits protein translation, whereas that of PKR-ND does not. Co-expression of PKR-ND and PKR-KD promotes their interaction with PKR, PKR and elF2- $\alpha$ phosphorylation and suppresses protein translation better than PKR-KD alone. Our findings suggest a caspase-dependent mode of activation of PKR in apoptosis in which the PKR-KD fragment interacts with and activates intact PKR. PKR-ND facilitates the interaction of PKR-KD with full-length PKR and thus the activation of the kinase and amplifies the translation inhibitory signal.

Cell Death and Differentiation (2007) 14, 1050-1059. doi:10.1038/sj.cdd.4402110; published online 23 February 2007

Double-stranded RNA (dsRNA) is a typical by-product of viral infection. Cells respond to dsRNA presented from with or without, for example, via RIG-I or MDA-5 or Toll-like receptor 3 (TLR3) signaling pathways. ${ }^{1,2}$ TLRs detect specific molecular features of microorganisms and through differential use of Toll/IL-1R (TIR)-domain-containing adapter proteins, activate signaling pathways leading to activation of nuclear factor $-\kappa \mathrm{B}$ (NF- $\kappa$ B) and IRF-3 and the production of type I interferons. ${ }^{3}$ Interferons enhance the cellular antiviral response by inducing expression of protective proteins many of which are activated by dsRNA. ${ }^{4}$ One of the major cellular antiviral proteins is the serine-threonine kinase, dsRNA-activated protein kinase (PKR). ${ }^{5}$ The protein consists of two functionally distinct domains: an N-terminal regulatory domain (ND) and a Cterminal catalytic kinase domain (KD). The regulatory domain contains two dsRNA-binding motifs, followed by a spacer. Binding of dsRNA induces PKR dimerization and allows the exposure of the catalytic site, autophosphorylation and activation of the kinase. ${ }^{6-9}$ Once activated, dsRNA is dispensable for further substrate phosphorylation. Activated PKR can phosphorylate the $\alpha$ regulatory subunit of the eukaryotic initiation factor 2 (elF2) and inhibit mRNA translation. During initiation of mRNA translation elF2 forms a ternary complex with a methionyl initiator tRNA (Met-tRNAi-Met) and GTP that delivers the Met-tRNAi-Met to the 40S ribosomal subunit at the proper AUG initiation codon. Subsequent loading of elF2 with Met-tRNAi-Met and exchange of GDP by GTP is catalyzed by elF2B. Phosphorylated elF2- $\alpha$ converts the elF2 complex into a competitive inhibitor of elF2B, resulting in blockage of protein synthesis. ${ }^{10}$ As elF2B is a limiting component of the cellular translation machinery, phosphorylation of only a fraction of the cellular elF2- $\alpha$ is sufficient to impair severely translation initiation.

Infection by many viruses triggers immune and inflammatory responses, and may result in death of the cellular host. Indeed, cell suicide followed by phagocytosis is another way to clear a persistent virus that other cellular defense mechanisms failed to overcome. ${ }^{11}$ We have shown that in addition to increasing the capacity of cells to resist viral infection, type-I and type-II interferons can sensitize cells to external dsRNA-induced apoptosis and necrosis and demonstrated that dsRNA induced apoptosis but not necrosis requires FADD and caspase- $8 .{ }^{12}$

In addition to elF2- $\alpha$ phosphorylation and inhibition of translation, PKR is involved in regulation of the activation of several transcription factors such as NF- $\kappa \mathrm{B}, \mathrm{p} 53$, or STATs.

\footnotetext{
${ }^{1}$ Laboratory of Cellular Microbiology, Pasteur Institute, Rue Engeland 642, B-1180 Brussels, Belgium; ${ }^{2}$ Molecular Signalling and Cell Death Unit, Department for Molecular Biomedical Research, VIB and Ghent University, Technologiepark 927, B-9052 Zwijnaarde, Belgium and ${ }^{3}$ Laboratory of Enzymology, Pasteur Institute, Rue Engeland 642, B-1180 Brussels, Belgium

${ }^{*}$ Corresponding author: M Kalai, Unit of Molecular Microbiology, Institute Pasteur of Brussels, Engelandstraat 642, Brussels 1180, Belgium. Tel: + 3223733114 ; Fax: + 322373 3282; E-mail: mkalai@ pasteur.be

${ }^{4}$ All these authors contributed equally.

Keywords: apoptosis; dsRNA; necrosis; PKR; RIP1

Abbreviations: Ac-DEVD-amc, acetyl-Asp(OMe)-Glu(OMe)-Val-Asp(OMe)-aminomethylcoumarin; ds, double-stranded; elF2- $\alpha$, eukaryotic initiation factor 2- $\alpha$; EGFP enhanced GFP; GFP, green fluorescent protein; HRP, horseradish peroxidase; IFN, interferon; JE, Jurkat E; IP, immunoprecipitation; KD, kinase domain; ND, N-terminal domain; PAGE, polyacrylamide gel electrophoresis; PARP, poly(ADP-ribose) polymerase; PBS, phosphate-buffered saline; PKR, dsRNA-activated protein kinase; PMSF, phenylmethylsulfonyl fluoride; RIP1, receptor-interacting protein kinase 1; TNF, tumor necrosis factor; WB, Western blot; wt, wild type; zVAD-fmk, benzyloxycarbonyl-Val-Ala-DL-Asp(OMe)-fluoromethylketone

Received 20.2.06; revised 11.1.07; accepted 11.1.07; Edited by B Zhivotovsky; published online 23.02.07
} 
Moreover, apoptosis induced by LPS, tumor-necrosis factor $\alpha$ (TNF- $\alpha$ ), viral infection, or serum starvation was suggested to require $\mathrm{PKR},{ }^{5,13,14}$ whereas induction of apoptosis by $\mathrm{PKR}$ was suggested to involve the activation of the FADD/caspase8 pathway by a mechanism independent of Fas and TNFR. ${ }^{15}$

We demonstrated before that cleavage of PKR by caspases at aspartate 251 occurs in apoptosis and leads to PKR activation, elF2- $\alpha$ phosphorylation, and inhibition of translation. ${ }^{16}$ In contrast the induction of necrosis does not lead to shut down of protein synthesis but coincides with NF- $\kappa \mathrm{B}-$ and p38MAPK-mediated upregulation and secretion of the proinflammatory cytokine IL-6. ${ }^{17,18}$

Here, we studied dsRNA-induced apoptosis and necrosis, investigated the role of receptor interacting protein kinase-1 (RIP1) and the fate of PKR and its substrate elF2- $\alpha$, and analyzed the mechanism of PKR activation by caspases in detail.

\section{Results}

PKR cleavage, phosphorylation and activation occur in dsRNA-induced apoptosis but not in necrosis. We demonstrated before that Jurkat cells treated with interferon (IFN) + dsRNA respond by apoptosis. ${ }^{12}$ When the treated cells were deficient for FADD or caspase-8, or when treatment was carried out in the presence of the pancaspase inhibitor benzyloxycarbonyl-Val-Ala-DL-Asp(OMe)fluoromethylketone (zVAD-fmk) cells responded by rapid necrosis. ${ }^{12}$ Treatment of Jurkat E (JE) and JB6 Jurkat cells with dsRNA $(100 \mu \mathrm{g} / \mathrm{ml}$ poly I:poly C), rapidly induced cell death (Figure 1). The morphology of dying JE cells treated with either anti-Fas or dsRNA was typically apoptotic (Figure 1a). In contrast the JB6 mutant cell line, lacking caspase- 8 and overexpresses $\mathrm{Bcl} 2$, responded by necrosis (Figure 1a). As demonstrated by DEVDase activity and poly(ADP-ribose) polymerase (PARP) cleavage, caspase activation occurred in JE cells treated with either dsRNA or anti-Fas, but did not occur in dsRNA treated JB-6 cells (Figure 1b). Western blot (WB) analysis with antibodies specific for the $\mathrm{N}$ - and C-terminal parts of PKR, respectively, demonstrated that cleavage of the protein occurred in JE cells treated with either anti-Fas or dsRNA but not in dsRNAtreated JB6 cells, which express similar PKR amounts (Figure 1b). Analysis of the phosphorylation state of PKR demonstrated that the protein is highly phosphorylated in a

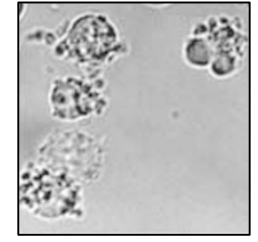

b

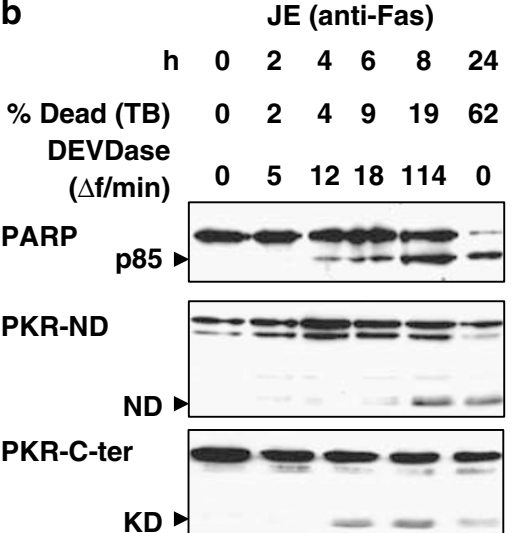

C

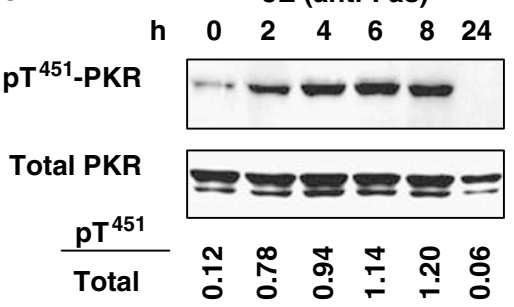

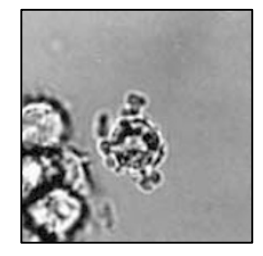

JE (dsRNA)

$\begin{array}{llllll}0 & 2 & 4 & 6 & 8 & 24\end{array}$

$\begin{array}{llllll}0 & 3 & 10 & 11 & 21 & 40\end{array}$

$\begin{array}{llllll}0 & 0 & 0 & 33 & 9 & 0\end{array}$
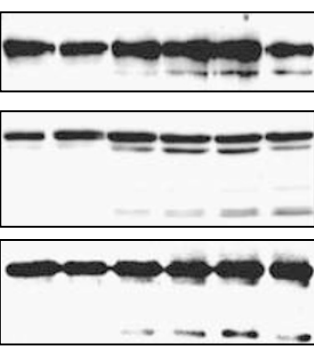

JE (dsRNA)
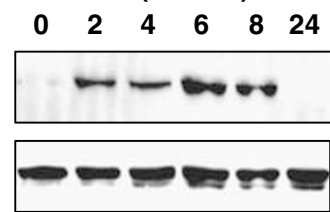

ষั
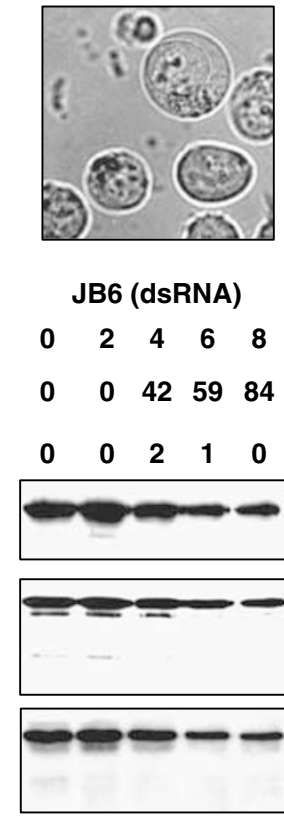

JB6 (dsRNA)
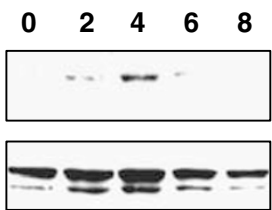

б.

Figure 1 PKR is cleaved and phosphorylated in dsRNA-induced apoptosis but not in necrosis, in Jurkat cells. (a) Light microscopy analysis of JB6 (right) and Jurkat E (JE) (middle) cells treated with dsRNA (100 $\mu \mathrm{g} / \mathrm{ml})$. Apoptotic JE treated with agonistic anti-Fas antibody $(30 \mathrm{ng} / \mathrm{ml})$ (left) was added as control. (b) At different time points after treatment, cells were collected and their mortality was determined by Trypan blue (TB) exclusion. Cell lysates were used to determine caspase activity by Ac-DEVD-amc proteolysis and PARP and PKR cleavage by WB analysis. ND, N-terminal domain; KD, kinase domain; p85, PARP fragment. Arrowheads indicate cleavage product. (c) Cell lysates used in (b) were analyzed for PKR phosphorylation at threonine-451, during dsRNA-or anti-Fas-induced apoptosis in JE cells and in dsRNA-induced necrosis in JB6 cells, by WBs. Immunoreactive signal was quantified by densitometry and the ratio between phospho-PKR and total PKR was determined 
apoptotic JE cells (Figure 1c). Treatment of JE cells with either anti-Fas or dsRNA led to a similar PKRphosphorylation level (Figure 1c). The extent of PKR phosphorylation in dsRNA treated JB6 cells was significantly lower (Figure 1c). These results suggest that PKR is cleaved and phosphorylated in apoptosis but not in necrosis.

RIP1 kinase may play an important role in signaling to dsRNA-induced apoptosis and necrosis. In addition to NF- $\kappa \mathrm{B}$ and IRF-3 activation, ${ }^{19}$ signaling to apoptosis in response to external dsRNA was suggested to be TLR3 TIRadapter (TRIF)-dependent and to occur via interaction with the RIP1 and Fas/Apo-1-associated death domain (FADD), thus leading to caspase-8 activation. ${ }^{20}$ When we transiently coexpressed green fluorescent protein (GFP) with either TRIF, RIP1, FADD, or caspase-8 in HEK293T cells, transfected cells died by apoptosis (data not shown).

The importance of RIP1 in signaling to necrotic cell death mediated by Fas or TNF was demonstrated in several reports. ${ }^{21-23}$ Therefore, we used RIP1-deficient $\left(\mathrm{RIP}^{-}\right)$Jurkat cells to study the involvement of the protein in dsRNA-induced apoptosis and necrosis. When we treated RIP1- Jurkat cells with IFN + dsRNA, in the presence or absence of zVAD-fmk, they failed to respond by necrosis or apoptosis in contrast to parental $\left(\mathrm{RIP}^{+}{ }^{+}\right.$) cells (Figure $2 \mathrm{a}$ and b). Treatment of the cells with anti-Fas, demonstrated that, in the RIP1-positive and -negative Jurkat cells, the FADD/ caspase-8 pathway was intact and effectively blocked by treatment with zVAD-fmk (Figure $2 b$ ). These results suggest that RIP1 is required for dsRNA-induced apoptosis and necrosis.

Similar to RIP1 most of the cellular PKR is probably not a monomer and may be included in protein complexes. Although PKR was suggested to be recruited within the cell to different complexes, ${ }^{5}$ until recently inactive PKR was thought to be a monomer. However, a new report suggests that inactive PKR is a homodimer. ${ }^{24}$

To determine if cellular PKR is a monomer or recruited to complexes, we analyzed cell extracts of Jurkat E cells by gel filtration (Figure 2c). Similar to RIP1, PKR was suggested to participate in TNFRI and TLR3 signaling complex formation leading to NF- $\kappa$ B activation. ${ }^{25,26}$ We demonstrated recently the formation of a large molecular weight complex, including RIP1 in Hek293T cell lysates upon incubation at $37^{\circ} \mathrm{C} .^{27}$ Therefore, we compared the molecular weights of complexes containing either RIP1 or PKR in the Jurkat E cell extracts following incubation for $1 \mathrm{~h}$ at 4 or $37^{\circ} \mathrm{C}$.

WB analysis demonstrated that at $4^{\circ} \mathrm{C}$ RIP1 and PKR are eluted in similar fractions corresponding to sizes up to about $440 \mathrm{kDa}$ (Figure 2c). Most of the PKR was eluted in fraction 21 corresponding to the size expected for a dimer of the protein. Following incubation at $37^{\circ} \mathrm{C}$ a large part of RIP1 and most of PKR was recruited to higher molecular weight complexes larger than $670 \mathrm{kDa}$ (Figure 2c).

Immunoprecipitaion of RIP1 and WB analysis demonstrated that, at $37^{\circ} \mathrm{C}$ but not at $4^{\circ} \mathrm{C}$, the protein co-precipitated with PKR (Figure $2 \mathrm{~d}$ ). These results suggest that most of the cellular PKR is not a monomer and is included in complexes.
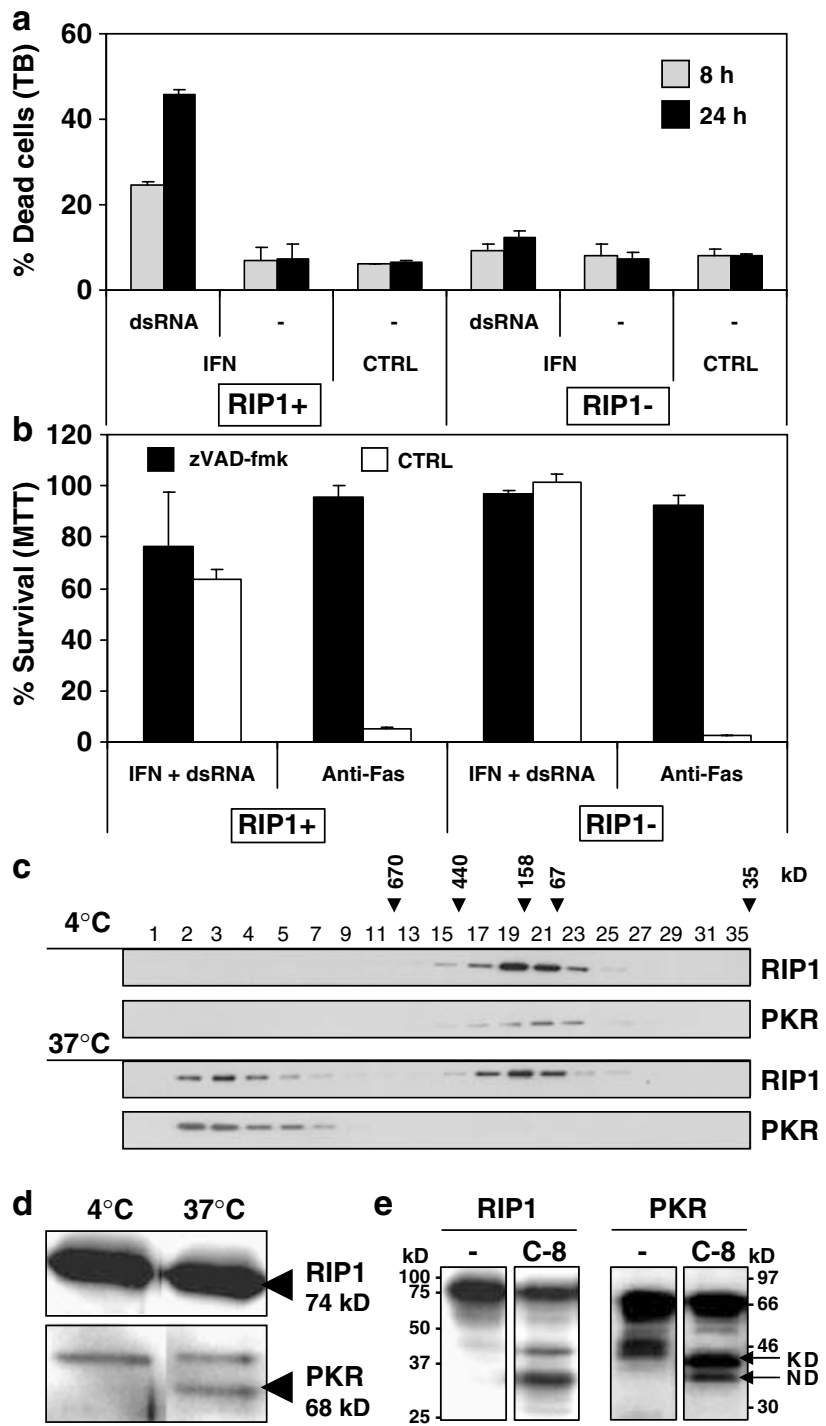

Figure 2 Involvement of RIP1 in dsRNA-induced apoptosis and necrosis; evaluation of a possible interaction with PKR. (a) RIP1-deficient Jurkat cells are resistant to dsRNA-induced cell death. The cytotoxic effects of the combination of dsRNA and IFN- $\gamma$ were tested on RIP-positive (RIP ${ }^{+}$) and RIP-negative (RIP ${ }^{-}$) Jurkat cells. Following $24 \mathrm{~h}$ of pretreatment with or without IFN- $\gamma(1000 \mathrm{IU} / \mathrm{ml})$, cells were exposed to dsRNA $(100 \mu \mathrm{g} / \mathrm{ml})$. Cell death was determined by TB exclusion 8 and $24 \mathrm{~h}$ later. (b) RIP1-deficient Jurkat cells are resistant to dsRNA-induced apoptosis and necrosis. The cytotoxic effects of the combination of dsRNA $(100 \mu \mathrm{g} / \mathrm{ml})$ and IFN- $\gamma(1000 \mathrm{IU} / \mathrm{ml})$ and of anti-Fas $(30 \mathrm{ng} / \mathrm{ml})$ were tested on $\mathrm{RIP}^{+}$and $\mathrm{RIP}^{-}$ Jurkat cells in the presence or absence of ZVAD-fmk $(25 \mu \mathrm{M})$. Cell survival was measured by MTT, $24 \mathrm{~h}$ after dsRNA or anti-Fas treatment. (c) JE cell lysates were incubated for $1 \mathrm{~h}$ incubation at 4 or $37^{\circ} \mathrm{C}$ and analyzed by size-exclusion chromatography and Western blotting with the indicated antibodies. Gel filtration fraction numbers and molecular marker sizes (arrow heads) are as indicated. (d) WB analysis for PKR and RIP1, following IP of the latter from Jurkat E cell lysates that were incubated for $1 \mathrm{~h}$ at 4 or $37^{\circ} \mathrm{C}$. (e) Cleavage of RIP1 and PKR by caspase-8. In vitro translated $\mathrm{S}^{35}$-labelled RIP1 and PKR were incubated with or without purified recombinant caspase- 8 for $1 \mathrm{~h}$ at $37^{\circ} \mathrm{C}$, reaction products were separated by SDSPAGE and gels were dried and exposed to film. C-8 indicates caspase- 8 . The bands corresponding to the PKR-KD and -ND fragments are indicated by arrows

Although recruitment of PKR and RIP1 together to the same high-molecular-weight complex is possible, within the cell, this most probably does not occur spontaneously. 
PKR phosphorylation in apoptosis is caspasedependent. Our and others in vitro proteolysis studies suggest that both PKR and RIP1 are caspase-8 substrates (Figure 2e). Although caspase-mediated proteolysis of RIP1 was suggested to promote apoptosis by inhibition of NF- $\kappa \mathrm{B}$ activation and signaling to necrosis ${ }^{28}$ that of PKR was suggested to activate the kinase and inhibit mRNA translation. ${ }^{16}$

We analyzed the phosphorylation state of PKR and its substrate elF2- $\alpha$ in JE cells treated with dsRNA in the presence of the caspase inhibitor zVAD-fmk. WB analysis demonstrated clearly that zVAD-fmk prevented the induction of PKR and elF2- $\alpha$ phosphorylation in cells treated with dsRNA (Figure 3 ). These results suggest that PKR and elF2- $\alpha$ phosphorylation in external dsRNA-induced apoptosis is caspase-dependent.

Full-length PKR and PKR-KD can phosphorylate and activate each other. We have demonstrated before that the PKR-KD fragment can phosphorylate elF2- $\alpha$ in vitro and that overexpression of PKR-KD but not of the catalytically inactive PKR-KD-K296R mutant leads to inhibition of translation in cells. ${ }^{16} \mathrm{X}$-ray crystal structure analysis of the PKR KD (aa 258-551) demonstrates that the fragment is catalytically active and forms a dimer. Binding to elF2- $\alpha$ occurs via the $\mathrm{C}$-terminal catalytic lobe and dimerization is mediated by the $\mathrm{N}$-terminal lobe. ${ }^{8,9}$

We wondered whether the caspase-mediated PKR fragments could affect the activation state of the remaining fulllength PKR. We tested the capacity of each of the fragments to interact with full-length PKR in cells. We used the catalytically inactive K296R mutants of PKR and PKR-KD,

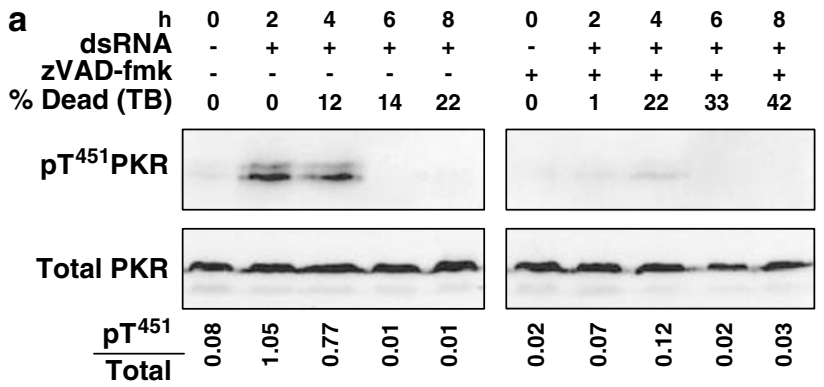

b

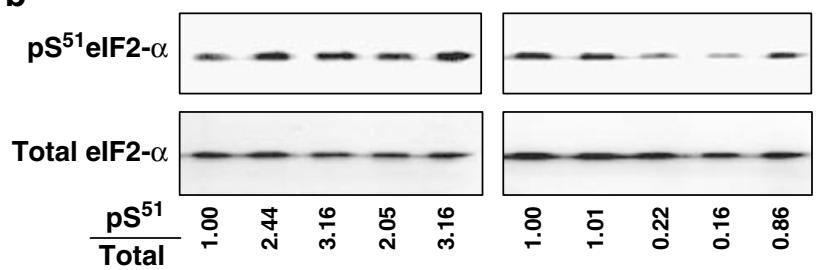

Figure 3 Inhibition of caspases prevents PKR and elF2- $\alpha$ phosphorylation in dsRNA-induced cell death. WB analysis carried out to determine the level of PKR (a) and elF2- $\alpha$ (b) phosphorylation in dsRNA-induced apoptosis and necrosis in JE cells treated or not with $50 \mu \mathrm{M} \mathrm{zVAD}$-fmk for $30 \mathrm{~min}$ before and during exposure to $100 \mu \mathrm{g} / \mathrm{ml}$ dsRNA. At different time points after dsRNA treatment, cellular mortality was determined by TB exclusion, cells were collected and protein extracts were analyzed by Western blotting using the corresponding antibodies. Immunoreactive signal was quantified densitometrically and the ratio between phosphorylated and total PKR and elF2- $\alpha$ was determined to avoid problems owing to inhibition of mRNA translation. Co-expression of PKR-K296R with either PKR-ND or PKRKD-K296R in HEK293T cells followed by immunoprecipitation (IP) demonstrated that both fragments co-precipitated with full-length PKR (Figure 4).

Next, we analyzed the effect of overexpression of the PKRND or -KD fragments on the phosphorylation of full-length PKR and elF2- $\alpha$, and on de novo protein translation. Previous reports suggested that a PKR fragment corresponding to amino acids (aa) 1-228 may act as a PKR inhibitor. ${ }^{6,29}$ Overexpression of PKR-ND ${ }_{1-228}$ or PKR-ND (aa 1-251) in Hek293T cells did not lead to phosphorylation of endogenous PKR (Figure 5, left panel). The residual elF2- $\alpha$ phosphorylation level was slightly lower compared to controls and the expression of the co-transfected reporter GFP was clearly increased, suggesting that these PKR fragments may inhibit full-length PKR.

Overexpression of full-length PKR led to a strong phosphorylation of PKR and elF2- $\alpha$ and inhibition of GFP translation (Figure 5, right panel). Similar results were obtained with overexpressed PKR-KD with the addition that both endogenous wild-type (wt) PKR and the KD fragment were clearly phosphorylated. Although the inactive PKRK296R and PKR-KD-K296R mutants were incapable of phosphorylating elF2- $\alpha$ and inhibiting GFP translation they were clearly phosphorylated, suggesting that they too interact with endogenous wt PKR. These results suggest that PKR and PKR-KD can interact and phosphorylate each other.

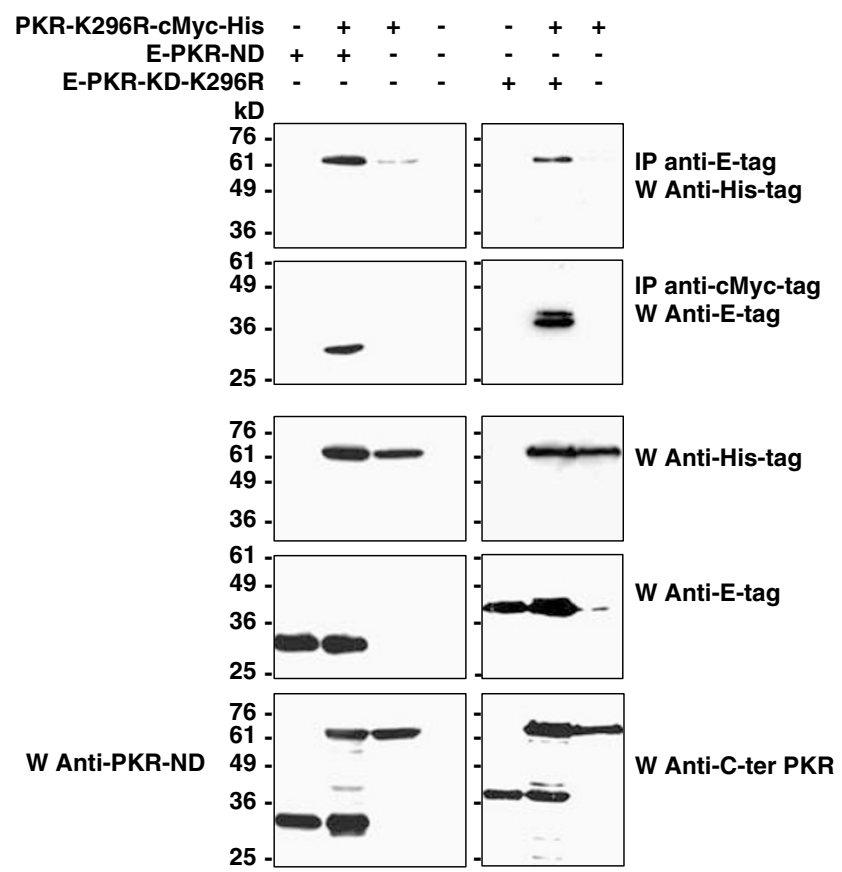

Figure 4 PKR-ND and PKR-KD co-immunoprecipitate with full-length PKR. IP assays were performed using the indicated antibodies and lysates of HEK293T cells transiently co-transfected with a plasmid encoding GFP together with an empty pEF6A vector (Vec) and/or plasmids encoding full-length cMyc-His-tagged K296R mutant PKR together with either E-tagged PKR-ND (left) or E-tagged PKR-KDK296R (right). Aliquots of the same lysates were also analyzed directly by SDSPAGE and Western blotting as indicated. IP, immunoprecipitation; WB, Western blotting 

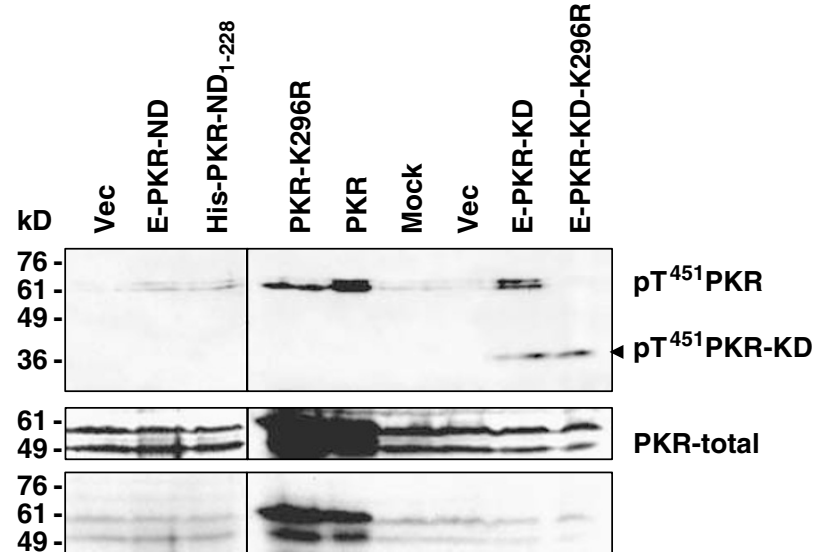

49

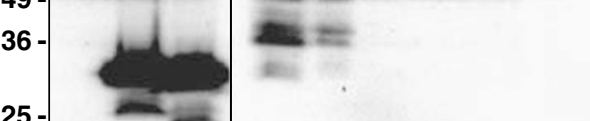

PKR-ND

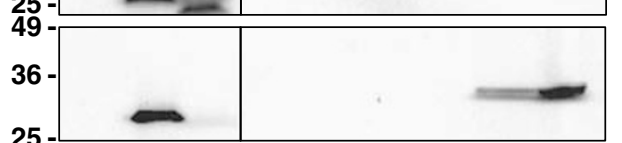

E-tag

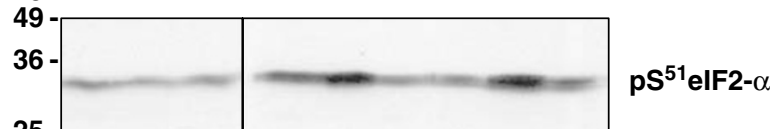

25
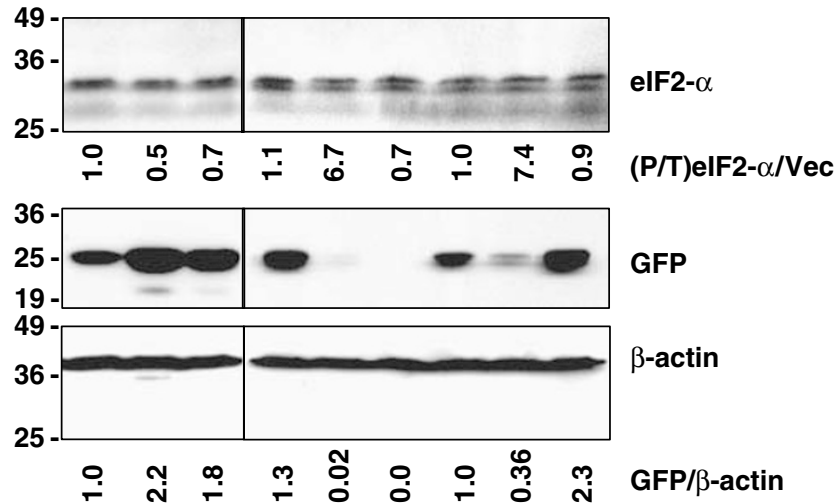

Figure 5 Overexpression of PKR-KD but not of PKR-ND leads to PKR and elF2- $\alpha$ phosphorylation and to inhibition of translation. WB analysis using the indicated antibodies and lysates of HEK293T cells transiently co-transfected with a plasmid encoding GFP together with an empty $p E F 6 A$ vector $(V e c)$ or expressing $E$ tagged PKR-ND, His-tagged PKR-ND ${ }_{1-128}$, full-length PKR, the inactive PKR mutant K296R, E-tagged PKR-KD or the inactive E-tagged PKR-KD-K296R, respectively as indicated. Immunoreactive signal for GFP, phosphorylated and total elF2- $\alpha$ was quantified densitometrically and calibrated in comparison to that obtained with the empty vector (vec). The ratio between phosphorylated and total (P/T) elF2- $\alpha$ was also determined. Mock indicates that no DNA was transfected

Although PKR-ND can also co-precipitate with full-length PKR it cannot activate it by its own.

PKR-ND increases the capacity of PKR-KD to interact with full-length PKR, to phosphorylate PKR and elF2- $\alpha$ and to inhibit translation. Although complexes containing PKR together with PKR-ND or PKR-KD are formed, the fragments seem to have opposite effects on the phosphorylation and activation state of the full-length protein. Previous studies suggested that PKR-ND may act as a dominant-negative by binding to the $\mathrm{N}$-terminal part of a

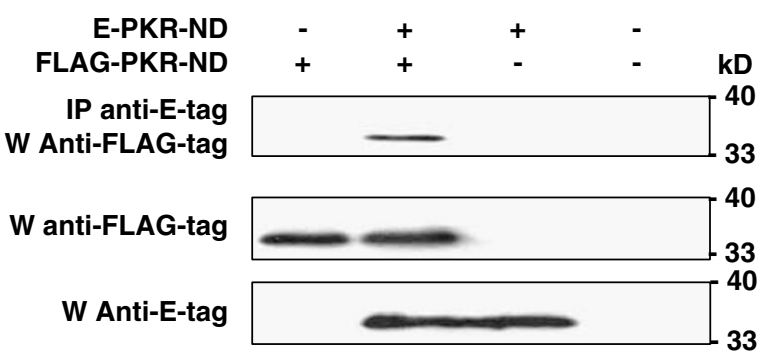

b

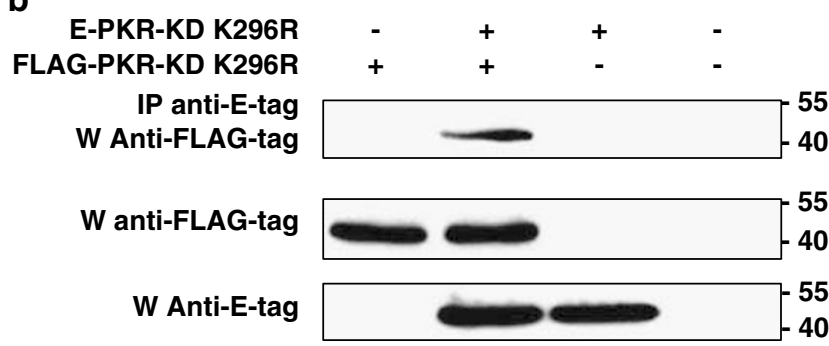

C

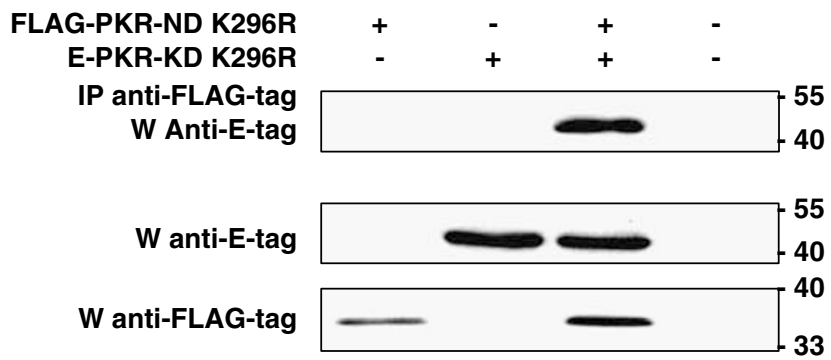

Figure 6 Homo- and hetero-co-immunoprecipitation of PKR-ND and PKR-KD. Immunoprecipitation assays performed using the indicated antibodies and lysates of HEK293T cells transiently co-transfected with a plasmid encoding GFP together with an empty pEF6A vector (Vec) and/or plasmids encoding: (a) E-tagged PKR-ND and FLAG-tagged PKR-ND, (b) E-tagged PKR-KD-K296R and FLAG-tagged PKRKD-K296R, or (c) FLAG-tagged PKR-ND and E-tagged PKR-KD-K296R. Aliquots of the same lysates were also analyzed directly by SDS-PAGE and Western blotting as indicated. IP, immunoprecipitation; WB, Western blotting

PKR thus preventing the homodimerization and activation of the full-length protein. ${ }^{6,29}$ Alternatively NMR analysis suggested that the $\mathrm{C}$-terminal part of PKR-ND may bind directly to the KD of PKR, thus preventing the homodimerization and activation of the full-length protein. ${ }^{7,30}$ As during apoptosis both the ND and KD fragments occur simultaneously and at the same place, we decided to explore how they interact with each other within the cell. Co-expression of E-tagged PKR-ND with FLAGtagged PKR-ND in Hek293T cells followed by IP analysis demonstrated that the proteins co-precipitate (Figure 6a). A similar experiment using $\mathrm{E}$ - and FLAG-tagged PKR-KD$\mathrm{K} 296 \mathrm{R}$ demonstrated that the KD is also capable of coprecipitating (Figure 6b). Co-expression of E-tagged PKRND with FLAG-tagged PKR-KD-K296R followed by IP showed that the two are also present in the same complex (Figure 6c). If PKR-ND and PKR-KD interact with each other directly than PKR-ND might function as an inhibitor of PKR$K D$, resulting in a decrease in the kinase activity. However, as both PKR-ND and PKR-KD can bind full-length PKR 


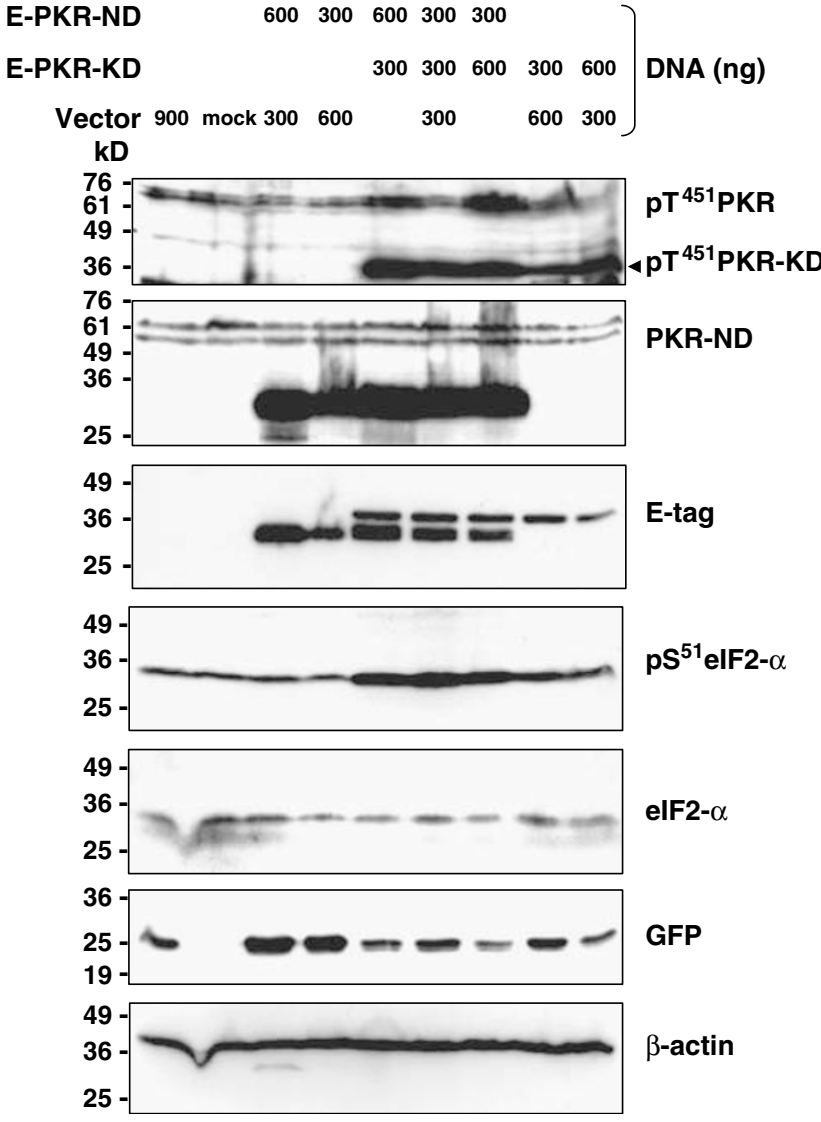

Figure 7 Co-expression of PKR-ND and PKR-KD leads to a strong activation of PKR, elF2- $\alpha$ phosphorylation and inhibition of translation. WB analysis using the indicated antibodies and lysates of Hek293T cells transiently co-transfected with a plasmid encoding GFP together with an empty $\mathrm{pEF6A}$ vector or with different amounts of pEF6A plasmid expressing E-tagged PKR-ND and E-tagged PKR-KD as indicated. Mock indicates that no DNA was transfected

(Figure 4) their apparent co-immunoprecipitation might actually occur via endogenous PKR. PKR-ND might then facilitate the interaction of PKR-KD with full-length PKR and thereby increase the kinase activity. Therefore, we tested the effect of co-expression of PKR-ND with PKR-KD on PKR and elF2- $\alpha$ phosphorylation and on GFP expression. Our results suggest that in cells co-expressing PKR-ND and PKR-KD the phosphorylation of full-length PKR, PKR-KD, and elF2- $\alpha$ and the inhibition of GFP expression is higher than in cells expressing PKR-KD alone (Figure 7). Immunoprecipitation analysis of PKR-K296R-cMyc-His and E-tag-PKR-KDK296R in the presence or absence of PKR-ND demonstrated that PKR-ND may facilitate the integration of PKR-KD in a complex containing full-length PKR (Figure 8a). Indeed, the integration of PKR-KD in that complex increased in a direct correlation with the increase in the amount of the available PKR-ND (Figure 8b).

To determine the size of the complexes containing these tagged PKR, PKR-KD, and PKR-ND we carried out gel filtration and WB analysis of lysates Hek293T cells overexpressing the three proteins (Figure $8 \mathrm{c}$ ). At conditions similar to our co-immunoprecipitaion experiments $\left(4^{\circ} \mathrm{C}\right)$, most of the PKR-KD was eluted as a protein smaller than $67 \mathrm{kDa}$

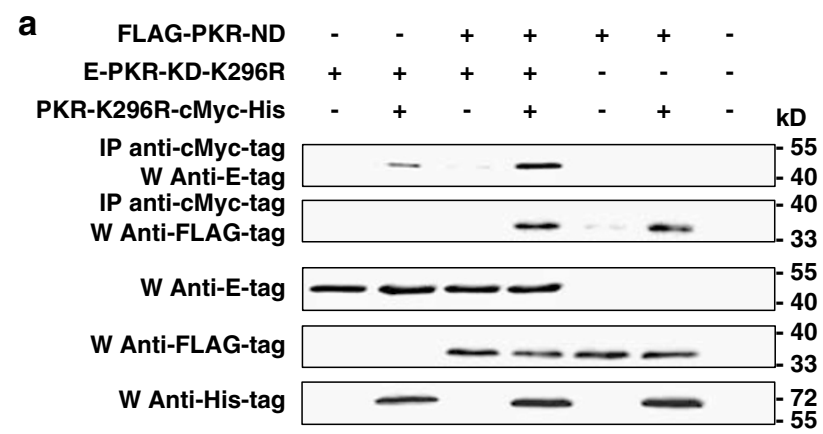

b
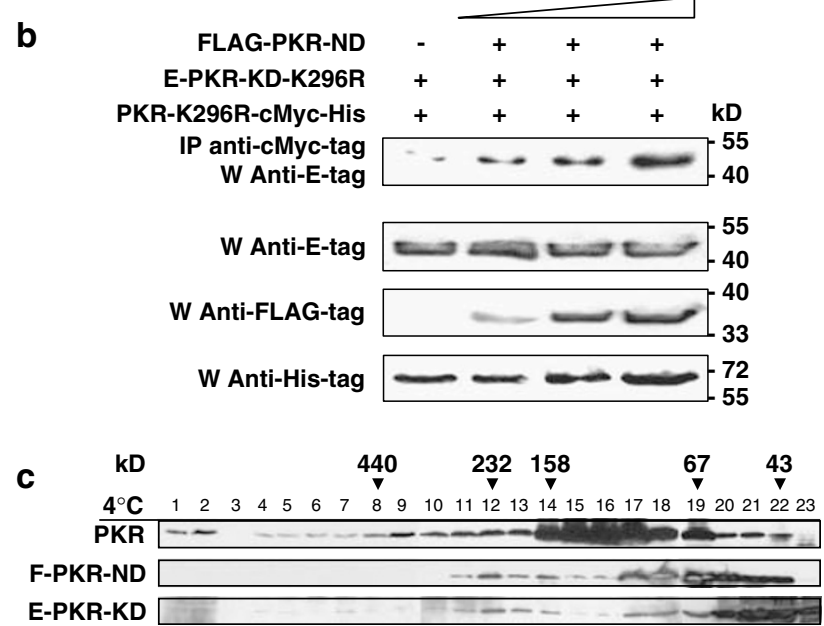

Figure 8 PKR-ND facilitates the interaction of PKR-KD with full-length PKR. Co-IP assays performed using the indicated antibodies and lysates of Hek293T cells transiently co-transfected with a plasmid encoding GFP together with an empty pEF6A vector (Vec) and/or (a) equal amounts of plasmids encoding; FLAG-tagged PKR-ND, E-tagged PKR-KD-K296R and cMyc-His-tagged full-length PKR-K296R, as indicated. (b) Equal amounts of plasmids encoding E-tagged PKR-KD-K296R and cMyc-His-tagged full-length PKR-K296R and increasing amounts of FLAGtagged PKR-ND $(+200,+400,+600 \mathrm{ng})$, as indicated. Aliquots of the same lysates were also analyzed directly by SDS-PAGE and Western blotting as indicated. IP, immunoprecipitation; W, Western blotting. (c) Co-elution of PKR and PKR-ND and PKR-KD after gel filtration of extracts of transfected Hek293T cells. Cell were transiently co-transfected with equal amounts of plasmids encoding; FLAG-tagged PKR-ND (FLAG-PKR-ND), E-tagged PKR-KD-K296R (E-PKR-KD) and cMyc-His-tagged full-length PKR-K296R (PKR). Following cell lysis proteins were separated by size exclusion chromatography at $4^{\circ} \mathrm{C}$ and fractions were analyzed by Western blotting. Gel filtration fraction numbers and molecular marker sizes (arrow heads) are as indicated

(fractions 20-23) and thus migrated, probably, mainly as a monomer (Figure 8c). However, some of the protein was also eluted between estimated sizes 70 and $100 \mathrm{kDa}$ and between 158 and $280 \mathrm{kDa}$, in fractions 17-19 and 11-14, respectively. Although the expected size of PKR-ND is about $37 \mathrm{kDa}$ the protein eluted mainly in fractions 17-22, with the center of the peak being around $70 \mathrm{kD}$ suggesting that it was part of a small complex and maybe a dimer. Here again another peak eluted in fractions 11-14, corresponding to 158-280 kD. Full-length PKR eluted mainly in fractions 14-19, ranging from 67 to $158 \mathrm{kD}$, suggesting that at least part of the protein was in a complex. Nevertheless, a substantial amount of PKR was also eluted in fractions 11-14 suggesting that complexes containing the three proteins together may exist within the cell. Taken 
together the above results suggest that both of the fragments resulting from the proteolysis of PKR by caspases during apoptosis are recruited to a complex containing full-length PKR and are probably collaborating in the activation of the intact kinase.

\section{Discussion}

Recent reports suggest that RIP1 is recruited to the TLR3TRIF pathway where it plays an important role in signal transduction leading to NF- $\kappa$ B activation and apoptosis. ${ }^{19,20}$ We demonstrated here that RIP1 is probably required not only for dsRNA-induced signaling to apoptosis but also for dsRNAinduced necrosis.

In its natural environment within the cell, PKR may interact with many other molecules. Indeed several reports demonstrated that the kinase is recruited to different complexes including those initiated by ligand-mediated activation of TLR3 and TNFR1. ${ }^{25,26}$ In the current report, we studied the fate of PKR in cells during dsRNA-induced apoptosis and necrosis. Our results suggest a new and alternative mode of activation of this protein kinase in apoptosis that may shed light on the mode of PKR activation in cells in general.

We demonstrate that $\mathrm{PKR}$ is readily phosphorylated and activated in anti-Fas or dsRNA-induced apoptosis but hardly in dsRNA-induced necrosis. Phosphorylation of PKR correlated in time with the appearance of PKR cleavage products. As seen before with TNFR1- and Fas-mediated apoptosis, PKR activation in dsRNA-induced cell death did not occur in cells treated with the pan-caspase inhibitor zVAD-fmk or in cells lacking caspase-8 and was therefore caspase dependent. ${ }^{16,17}$ Our current results suggest that in addition to phosphorylating elF2- $\alpha$, the resulting PKR-KD fragment is probably also capable of phosphorylating and activating fulllength PKR.

We demonstrate that the ND and the KD caspase mediated PKR fragments can interact with full-length PKR in cells. In the absence of PKR-KD, PKR-ND, acts as a dominant-negative inhibitor of full-length PKR. However, PKR-ND may also facilitate the interaction of PKR-KD with the full-length protein, thus increasing the amount of activated PKR in the cell and amplifying the translation inhibitory effect without a requirement for further PKR cleavage by caspases.

Currently, it is difficult do determine if the interactions between the PKR fragments and full-length PKR within the cell are direct or not. However, our gel filtration analysis does not exclude the possibility and most in vitro and NMR and X-ray crystallography studies support it. ${ }^{6-9,30,31}$

Until recently, common opinion was that inactive full-length PKR is a monomer that is activated via binding of dsRNA to the regulatory $\mathrm{N}$-terminal domain of the protein. Several previous studies support a dominant-negative role for PKRND and NMR studies suggested that this is because of the interaction of the C-terminal part of dsRBD2 with the kinase domain. ${ }^{6,29-31}$ Binding of dsRNA of the correct size allows dimerization of two PKR molecules via their PKR-NDs, thus liberating the KD for dimerization, trans/autophosphorylation and catalytic activation. In vitro studies and crystal structure analysis of the KD of PKR, demonstrate that in the absence of PKR-ND, PKR-KD forms a catalytically active homodimer in which the fragments are bound in parallel. ${ }^{8,9}$ However, an alternative model based on low resolution NMR and in vitro studies of PKR suggests that inactive PKR is a homodimer in which the two subunits are bound in an anti-parallel manner via their kinase domains leaving the dsRNA binding domains free. ${ }^{24}$ Activation occurs via the binding of dsRNA of the correct size, dimerization of the PKR-NDs and the alignment of the attached kinase domains in the parallel mode described for the active PKR-KD. $8,9,24$

In accordance with recent NMR studies, ${ }^{30}$ our results suggest that the PKR-ND fragment is acting in cells as an inhibitor of PKR in the absence of the PKR-KD fragment but is promoting the activation and the interaction of the later together with the full-length protein when the two fragments are co-expressed. This suggests that even without being covalently attached to the KD the ND fragment is regulating the activity of PKR and supports the idea PKR-ND is inhibiting the catalytic activity of the kinase by binding to the kinase domain. If the current suggestion that inactive PKR is a dimer is correct, than PKR activation by caspase-mediated cleavage as probably occurs during apoptosis should be much more efficient than the reconstruction we made by the coexpression of PKR-KD and -ND. This mode of activation may be compared to the cleavage-dependent conformation rearrangement activation of the caspases themselves. In such a model, PKR-KD and -ND are more likely to act in consort than separately. This mode of PKR activation is probably important for apoptosis in general and may represent an alternative allowing cells to inhibit the replication of some of the viruses capable of interfering with the more classical dsRNA-mediated PKR activation mechanism. ${ }^{32,33}$

Although dsRNA is a typical activator of PKR phosphorylation of the kinase and its substrate elF2- $\alpha$, these events were not prominent in dsRNA-induced necrosis and correlate well with our previous results demonstrating that contrary to apoptosis, in necrosis, de novo protein synthesis persists and coincides with activation of pro-inflammatory signaling and cytokine secretion. ${ }^{17,18}$ The classical mode of activation of PKR by dsRNA requires a direct interaction between the nucleic acid polymer and the kinase. It is possible that administration of dsRNA in the culture medium does not allow the interaction between the extracellular nucleic acid and the cytoplasmic dsRNA-binding kinase. This suggests that the cell death pathways studied here were initiated by the interaction of dsRNA with a cell surface receptor such as TLR3. ${ }^{20}$ Although our current results suggest that the catalytic activity of PKR does not play a major role in dsRNA-induced necrosis, we cannot exclude that the protein is required in this cell death process. In addition to elF2- $\alpha$ phosphorylation and inhibition of translation, PKR was reported to control the activation of several transcription factors such as NF- $\kappa \mathrm{B}, \mathrm{p} 53$, and STATs. ${ }^{5,13,14}$ Together with TRAF6, TAK1 and TAB2, $\mathrm{PKR}$ is also recruited to TLR3 upon binding of dsRNA. ${ }^{25}$ As seen before with RIP1, ${ }^{34}$ the catalytic activity of PKR is not required for NF- $\kappa$ B activation. ${ }^{35}$ Similar to RIP1, PKR can activate NF- $\kappa$ B via interaction with TRAFs and the I $\kappa$ B kinase (IKK) complex. ${ }^{27,36}$ Apoptosis coupled with phagocytosis is often considered as a 'clean death' preventing the release of the intracellular content of the cell. ${ }^{37}$ Could rapid PKR activation and inhibition of translation contribute to keep 
apoptotic cells immunologically silent? Indeed during the early stages of apoptosis, both RIP1 and PKR are cleaved, whereas RIP1 is eliminated and PKR is activated. RIP1 cleavage leads to inhibition of $\mathrm{NF}-\kappa \mathrm{B}$ activation and prevents necrosis, ${ }^{21,22,28}$ whereas PKR cleavage inhibits de novo protein production and promotes apoptosis. ${ }^{16}$ Therefore, cleavage of PKR and RIP1 may act to promote apoptosis while decreasing inflammatory signaling and necrosis.

\section{Materials and Methods}

Antibodies, cytokines, and reagents. Poly(I)-poly(C) synthetic dsRNA (Amersham Pharmacia Biotech, Rainham, UK) was dissolved at $3.5 \mathrm{mg} / \mathrm{ml}$ in water. Recombinant human IFN- $\gamma$ was from BioSource International (Camarillo, CA, USA). $\mathrm{CH}-11$ agonistic anti-Fas antibody was from (BioCheck). Anti-GFP antibody was purchased from Clontech (Palo Alto, CA, USA). Antibodies specific for the ND and KD of human PKR were from Transduction Laboratories (Lexington, KY) and Santa Cruz Biotechnology (Santa Cruz, CA, USA), respectively. Anti-phophorylated-PKR $\left[\mathrm{PT}^{451}\right]$ was from Biosource. Antibodies against phosphorylated and unphosphorylated elF2- $\alpha$ were from Biosource and Santa Cruz Biotechnology, respectively. Anti-PARP was from Biomol Research Laboratories and anti- $\beta$-actin was from ICN Biomedicals. The caspase peptide inhibitor ZVAD-fmk was from Bachem (Bubendorf, Switzerland). The caspase fluorogenic substrate acetyl$\operatorname{Asp}(\mathrm{OMe})$-Glu(OMe)-Val-Asp(OMe)-aminomethylcoumarin (Ac-DEVD-amc) was from Peptide Institute (Osaka, Japan). Anti-E-tag antibody, horseradish peroxidase (HRP) conjugated or not were from Amersham Biosciences, (Freiburg, Germany). HRP-conjugated anti-His tag was from Invitrogen (Carlsbad, CA, USA) and HRP-conjugated anti-FLAG was from Sigma. Monoclonal mouse anti-cMyc-tag antibody was produced and purified in house (J Leoen).

Gel filtration chromatography. Jurkat $E\left(10^{8}\right.$ cells $)$ were washed twice with phosphate-buffered saline (PBS) and resuspended in $0.5 \mathrm{ml} \mathrm{TE}$ buffer ( $30 \mathrm{mM}$ Tris, pH 7.5, 5 mM EDTA) supplemented with Complete ${ }^{\mathrm{TM}}$ protease inhibitors (Roche, Basel, Switzerland), $1 \mathrm{mM} \mathrm{NaF}$ and $20 \mathrm{mM} \beta$-glycerophosphate. After $10 \mathrm{~min}$ incubation in this hypotonic solution, cells were dounced until $80 \%$ were lysed as determined by Trypan blue exclusion. The lysate was adjusted to $120 \mathrm{mM} \mathrm{NaCl}$ and cellular debris was removed by centrifuging twice $20 \mathrm{~min}$ at $11000 \mathrm{~g}$ and $4^{\circ} \mathrm{C}$. Lysates were incubated for $1 \mathrm{~h}$ at 4 or $37^{\circ} \mathrm{C}$ and fractioned at $4^{\circ} \mathrm{C}$ on a Superdex 200 (10/30) column (Amersham Biosciences, Frieburg, Germany) equilibrated in TNE buffer ( $30 \mathrm{mM}$ Tris, $\mathrm{pH} 7.5,120 \mathrm{mM} \mathrm{NaCl}$ and $5 \mathrm{mM}$ EDTA). Fractions of $0.4 \mathrm{ml}$ were eluted at $0.5 \mathrm{~m} / \mathrm{min}$ after elimination of flow through. Column was calibrated with thyroglobulin $(670 \mathrm{kDa})$, ferritin $(440 \mathrm{kDa})$, adolase $(158 \mathrm{kDa})$, bovine serum albumin $(67 \mathrm{kDa})$, and b-casein $(35 \mathrm{kDa})$. Proteins were precipitated by addition of ice-cold Trichloroacetic acid (TCA) up to $10 \%$ final concentration, 30 min incubation on ice and $15 \mathrm{~min}$ centrifugation at 14000 r.p.m. Pellet was washed with ice-cold acetone, dried, solubilized in $40 \mu \mathrm{l}$ sample buffer and analyzed by sodium dodecyl sulfate-polyacrylamide gel electrophoresis (SDS-PAGE) and Western blotting.

Induction of cell death in Jurkat cells and measuring of caspase activity. RIP-negative (RIP ${ }^{-}$) and corresponding parental RIP positive $\left(\mathrm{RIP}^{+}\right.$ Jurkat cells were obtained from $\mathrm{Dr} B$ Seed ${ }^{38}$ whereas parental Jurkat $E$ cells and JB6 cells, deficient in caspase-8 and overexpressing Bcl-2, were kindly provided by Dr S Nagata. ${ }^{39}$ Jurkat cells were cultured in LPS-free conditions in RPMI supplemented with $10 \%$ fetal bovine serum, $1 \mathrm{mM} \mathrm{L-glutamine,} 100 \mathrm{U} / \mathrm{ml}$ penicillin and $100 \mu \mathrm{g} / \mathrm{ml}$ streptomycin.

For cell death experiments, Jurkat cells were seeded at $5 \times 10^{5} \mathrm{cells} / \mathrm{ml}$. Jurkat $\mathrm{E}$ and JB6 were treated or not with anti-Fas or dsRNA $16 \mathrm{~h}$ later. RIP ${ }^{-}$and RIP ${ }^{+}$ Jurkats were first treated or not for $24 \mathrm{~h}$ with IFN- $\gamma$ before exposure to anti-Fas or dsRNA. Where indicated inhibition of caspases was obtained by preincubating cells for 30 min with zVAD-fmk before stimulation with dsRNA. The percentage of dead cells after addition of anti-Fas or dsRNA was monitored by Trypan blue exclusion. At the indicated time $3.5 \times 10^{6}$ cells were collected by centrifugation and washed twice with ice-cold PBS. Protein extracts for immunoblot analysis were made by total lysis from $2.8 \times 10^{6}$ cells/sample with $200 \mu \mathrm{l}$ sample buffer containing $6 \% \mathrm{SDS}, 1.4 \mathrm{M}$ $\beta$-mercaptoethanol, $20 \%$ glycerol, $0.01 \%$ (w/v) bromophenol blue, and $125 \mathrm{mM}$ Tris- $\mathrm{HCl}, \mathrm{pH} 6.8$, and boiling for $10 \mathrm{~min}$.
Cell extracts for the measuring of DEVDase activity were prepared by lysing $0.7 \times 10^{6} \mathrm{cell} / \mathrm{s} / \mathrm{sample}$ on ice with $100 \mu \mathrm{l}$ of cell-free system buffer containing $220 \mathrm{mM}$ mannitol, $68 \mathrm{mM}$ sucrose, $2 \mathrm{mM} \mathrm{NaCl}, 2.5 \mathrm{mM} \mathrm{KH}_{2} \mathrm{PO}_{4}, 10 \mathrm{mM}$ Hepes, $\mathrm{pH}$ 7.4, $1 \mathrm{mM}$ aprotinin, $1 \mathrm{mM}$ leupeptin, and $100 \mu \mathrm{M}$ phenylmethylsulfonyl fluoride (PMSF), supplemented with $0.05 \%$ Nonidet-P40 and $1 \mathrm{mM}$ oxidized glutathione. Cell debris was removed by centrifugation and caspase activity was determined by incubating $25 \mu \mathrm{l}$ of the soluble fraction with $50 \mu \mathrm{M} \mathrm{Ac}$-DEVD-amc in $150 \mu \mathrm{l}$ cell-free system buffer, containing $220 \mathrm{mM}$ mannitol, $68 \mathrm{mM}$ sucrose, $2 \mathrm{mM} \mathrm{MgCl}, 2 \mathrm{mM}$ $\mathrm{NaCl}, 2.5 \mathrm{mM} \mathrm{PO} \mathrm{H}_{2} \mathrm{~K}, 0.5 \mathrm{mM}$ EGTA, $0.5 \mathrm{mM}$ sodium pyruvate, $0.5 \mathrm{mM}$ L-glutamine, $10 \mathrm{mM}$ HEPES-NaOH pH 7.4, and $10 \mathrm{mM}$ dithiothreitol. The release of fluorescent 7-amino-4-methylcoumarin was measured for $60 \mathrm{~min}$ at 2-min intervals by fluorometry (excitation at $360 \mathrm{~nm}$ and emission at $480 \mathrm{~nm}$ ) (Cytofluor; PerSeptive Biosystems, Cambridge, MA, USA); the maximal rate of increase in fluorescence was calculated $(\Delta F / \mathrm{min})$.

Cell survival assay (MTT). Jurkat cells were seeded at $2 \times 10^{4}$ cells per well, respectively, in 96-well plates. The next day cells were left untreated or were treated with IFN $\gamma .24 \mathrm{~h}$ later dsRNA $(100 \mu \mathrm{g} / \mathrm{ml})$ or anti-Fas were added. Cell survival was assessed $24 \mathrm{~h}$ later using 3-(4,5-dimethylthiazol-2-yl)-2,5diphenyltetrazolium bromide (MTT). The percentage of cell death was calculated using the equation $100 \% \times($ A595/655 treated cells -A595/655 medium)/(A595/ 655 untreated cells - A595/655 medium).

Western blot analysis. Lysates or immune-complexes were fractionated by SDS-PAGE and transferred to nitrocellulose membranes. Blocking, antibody incubation steps, and washing of the membrane were performed in PBS supplemented with $3 \%$ skimmed milk and $0.05 \%$ Tween 20 . Blots were incubated with the indicated primary or HRP-conjugated antibodies. Membranes incubated with primary antibodies were consequently incubated with HRPconjugated secondary antibodies to mouse and rabbit immunoglobulin (Amersham Pharmacia Biotech, Rainham, UK), or goat antibody (Santa Cruz Biotechnology) according to needs. Immunoreactive proteins were visualized using chemiluminescence and signals were captured by exposure to film (Amersham Pharmacia Biotech). Where indicated, bands on the luminographs were quantitated by densitometry using a Lumi-Imager workstation (Roche Molecular Biochemicals).

Microscopic analysis. Jurkat cells were seeded in eight-chambered cover glass and stimulated for the time indicated. Phase-contrast images were photographed using a Leica DM IRE2 equipped with a HCX PLAPO $\times 63$ lens (NA, 1.30) and a cool snap HQ camera PI $(10 \mu \mathrm{M})$.

Plasmids. Plasmid constructs were made using current molecular biology techniques. Human RIP1 cDNA cloned in-frame with N-terminal FLAG tag in pCR3 was a kind gift from Dr J Tschopp. Human PKR CDNA cloned in-frame with $\mathrm{N}$-terminal His tag in $\mathrm{pET} 15 \mathrm{~b}$ was a kind gift from Dr B Williams. pEF6-His-PKR$N_{1-228}$ was obtained by transferring the CDNA sequence coding for the first 228 amino acids of PKR together with the N-terminal His tag. pEF6-PKR was obtained by transferring the full-length PKR cDNA to $\mathrm{pEF} / \mathrm{Myc}$-His $\mathrm{C}$ (Invitrogen) in-frame with the C-terminal Myc/His tags as described before. ${ }^{16}$ pEF6-PKR-K296R, was generated by overlap polymerase chain reaction mutagenesis. pEF6A-E-PKR generated KD and pEF6A-E-PKR-KD-K296R were obtained by transferring the cDNAs coding for PKR and PKR K296R starting from Met251, in-frame with an $\mathrm{N}$-terminal E- tag (amino-acid sequence MGAPVPYPDPLEPRAAA), and inserted into a pEF6A/Myc-His A vector (Invitrogen). pEF6A-E-PKR-ND was obtained by inserting the cDNA coding for aa 1-250 of PKR instead of PKR-KD, in frame with the E-tag coding sequence. FLAG-tagged constructs were obtained by replacing, in frame, the CDNA encoding for E-tag by that of FLAG-tag (MDYKDDDDKAAA). pNLS-enhanced green fluorescent protein (EGFP) is a modified pEGFP-N1 plasmid (Clontech) encoding GFP with a nuclear localization signal. The plasmids, their sequences and maps are available at the plasmid collection of the belgian co-ordinated collections of microorganisms (BCCM) (http://bccm.belspo.be).

In vitro caspase-8-mediated RIP1 and PKR cleavage reactions. ${ }^{35}$ S-labeled PKR and RIP1 were produced by using pCDM8-PKR and pCR3-FLAG-RIP1 vectors $(1 \mu \mathrm{g})$ as templates for in vitro coupled transcription translation in a reticulocyte lysates system (Promega Biotech, Madison, WI, USA). Translation reaction $(2 \mu \mathrm{l})$ was incubated for $1.5 \mathrm{~h}$ at $37^{\circ} \mathrm{C}$ with $200 \mathrm{nM}$ recombinant-purified caspases-8 in a total volume of $25 \mu \mathrm{l}$ of cell-free system buffer containing $220 \mathrm{mM}$ mannitol, $68 \mathrm{mM}$ sucrose, $2 \mathrm{mM} \mathrm{NaCl}, 2.5 \mathrm{mM} \mathrm{KH}_{2} \mathrm{PO}_{4}$, 
$10 \mathrm{mM}$ HEPES, pH 7.4, $1 \mathrm{mM}$ aprotinin, $1 \mathrm{mM}$ leupeptin, and $100 \mu \mathrm{M}$ phenylmethylsulfonyl fluoride. ${ }^{16}$ The resulting cleavage products were analyzed on SDS-PAGE gels and autoradiography.

Transfection, co-immunoprecipitation and size-exclusion chromatography. HEK293T human embryonic kidney carcinoma cell line cells were cultured in Dulbecco's modified Eagle's medium supplemented with $10 \%$ fetal calf serum, $1 \mathrm{mM} \mathrm{L-glutamine,} 100 \mathrm{U} / \mathrm{ml}$ penicillin, and $100 \mu \mathrm{g} / \mathrm{ml}$ streptomycin. HEK293T cells were transfected using the calcium phosphate precipitation method. ${ }^{40}$ Cells $\left(2 \times 10^{5}\right.$ cells/well) were seeded the day before transfection in sixwell plates (Greiner). Cells were transfected for $24 \mathrm{~h}$, washed and incubated for another $24 \mathrm{~h}$ before lysates were prepared. Cells were harvested in PBS-A and lysed in ice-cold NP-40 lysis buffer (10 mM HEPES, pH 7.4, $250 \mathrm{mM} \mathrm{NaCl}, 0.1 \%$ NP-40, $5 \mathrm{mM}$ EGTA), supplemented with $1 \times$ complete protease inhibitor mix (Roche, Basel, Switzerland). Cell lysates $(0.5 \mathrm{ml})$ were clarified by centrifugation at $14000 \mathrm{~g}$ for $5 \mathrm{~min}$. For analysis of expression $50 \mu \mathrm{l}$ of each lyste were mixed with $50 \mu \mathrm{l} 2 \times$ sample buffer and boiled for $10 \mathrm{~min}$. The rest was divided into two tubes $225 \mu \mathrm{l}$ each and immunoprecipitated using anti-FLAG-tag antibody conjugated sepharose (Sigma) or specific antibodies, including anti-E-tag (Amersham Biosciences, Freiburg, Germany) or anti-Myc (Invitrogen, Carlsbad, CA, USA) in combination with $10 \mu \mathrm{l}$ protein G-Sepharose (Amersham Biosciences, Freiburg, Germany). Following $24 \mathrm{~h}$ incubation at $4^{\circ} \mathrm{C}$ on a turning wheel sepharose beads were washed 4-6 times in NP-40 lysis buffer and precipitates were eluted in sample buffer by 5 min incubation at $95^{\circ} \mathrm{C}$. Protein expression and IP were determined by immunoblot analysis.

For gel filtration analysis HEK293T cells $\left(4.8 \times 10^{6}\right)$ were co-transfected for $48 \mathrm{~h}$ in six-well plates with equal amounts ( $0.5 \mu \mathrm{g} /$ well) each of pEF6-E-PKR-KD-K296R, pEF6-FLAG-PKR-ND and pEF6-PKR-K296R. Cell lysates were prepared as described for co-immunoprecipitation, incubated for $1 \mathrm{~h}$ at 4 or $37^{\circ} \mathrm{C}$ and fractioned at $4^{\circ} \mathrm{C}$ on a Superdex 200 (XK16/60) column (Amersham Biosciences, Frieburg, Germany) equilibrated in NP-40 lysis buffer. Fractions of $2 \mathrm{ml}$ were eluted at 1 $\mathrm{ml} / \mathrm{min}$ after elimination of flow through. Column was calibrated with ferritin (440 kDa), catalase (232 kDa), adolase (158 kDa), bovine serum albumin (67 kDa), ovalbumin $(43 \mathrm{kDa})$, and chemotrypsin $(25 \mathrm{kDa})$. Fractions were supplemented with $125 \mu \mathrm{g} / \mathrm{ml}$ deoxycholate acid, $10 \mu \mathrm{g} / \mathrm{ml}$ ribonuclease A $(13.7 \mathrm{kDa})$, as a protein carrier, and proteins were precipitated with TCA and analyzed as described above for Jurkat cells.

Acknowledgements. We thank $\mathrm{W}$ Burm and $\mathrm{J}$ Leoen for their technical support, Dr B Williams (The Cleveland Clinic Foundation, Cleveland, OH, USA) for the human PKR cDNA and Dr J Tschopp (Institute of Biochemistry, University of Lausanne, BIL Biomedical Research Center, Lausanne, Switzerland) for the human RIP1 cDNA. We thank Dr S Nagata, Dr H Matumura (Department of Genetics, Osaka University Medical School, Suita, Japan) and Dr B Seed (Department of Molecular Biology, Massachusetts General Hospital, Boston, MA, USA) for kindly donating the various Jurkat cell lines used in this study. This work was supported by the Interuniversitaire Attractiepolen-V (IUAP-V), the Fonds voor Wetenschappelijk Onderzoek-Vlaanderen (Grants 3G.0006.01 and 3G.021199), the Belgian Federation against Cancer, EC-RTD (Grant QLG1-CT-1999-00739), the Ghent University cofinancing EU project (011C0300), GOA project (12050502) and the anti-cancer fond 'Fondation Rose et Jean Hoguet'. V Suin was supported by grants from 'Les Amis de l'Institut Pasteur de Bruxelles (ASBL)-De Vrienden van het Instituut Pasteur van Brussel (VZW)' and from 'Fondation Rose et Jean Hoguet'. She is currently a fellow with the anti-cancer fond 'Télévie (Fond National de la Recherche Scientifique)'.

1. Matsumoto M, Funami $K$, Oshiumi $H$, Seya $T$. Toll-like receptor 3: a link between toll-like receptor, interferon and viruses. Microbiol Immunol 2004; 48: 147-154.

2. Meylan E, Curran J, Hofmann K, Moradpour D, Binder M, Bartenschlager R et al. Cardif is an adaptor protein in the RIG-I antiviral pathway and is targeted by hepatitis $\mathrm{C}$ virus. Nature 2005; 437: 1167-1172.

3. Yamamoto M, Akirz S. TIR domain-containing adaptors regulate TLR signaling pathways. Adv Exp Med Biol 2005; 560: 1-9.

4. Samuel CE. Antiviral actions of interferons. Clin Microbiol Rev 2001; 14: 778-809, table of contents.

5. Williams BR. PKR; a sentinel kinase for cellular stress. Oncogene 1999; 18: 6112-6120.
6. Wu S, Kaufman RJ. A model for the double-stranded RNA (dsRNA)-dependent dimerization and activation of the dsRNA-activated protein kinase PKR. J Biol Chem 1997; 272: $1291-1296$.

7. Nanduri S, Rahman F, Williams BR, Qin J. A dynamically tuned double-stranded RNA binding mechanism for the activation of antiviral kinase PKR. Embo $\mathrm{J} 2000 ; 19$ 5567-5574.

8. Dar AC, Dever TE, Sicheri F. Higher-order substrate recognition of elF2alpha by the RNAdependent protein kinase PKR. Cell 2005; 122: 887-900.

9. Dey M, Cao C, Dar AC, Tamura T, Ozato K, Sicheri F et al. Mechanistic link between PKR dimerization, autophosphorylation, and elF2alpha substrate recognition. Cell 2005; 122 901-913.

10. Kimball SR. Eukaryotic initiation factor elF2. Int J Biochem Cell Biol 1999; 31: 25-29.

11. Fujimoto I, Pan J, Takizawa T, Nakanishi Y. Virus clearance through apoptosis-dependent phagocytosis of influenza A virus-infected cells by macrophages. J Virol 2000; 74: 3399-3403.

12. Kalai M, Van Loo G, Vanden Berghe T, Meeus A, Burm W, Saelens X et al. Tipping the balance between necrosis and apoptosis in human and murine cells treated with interferon and dsRNA. Cell Death Differ 2002; 9: 981-994.

13. Cuddihy AR, Wong AH, Tam NW, Li S, Koromilas AE. The double-stranded RNA activated protein kinase PKR physically associates with the tumor suppressor p53 protein and phosphorylates human p53 on serine 392 in vitro. Oncogene 1999; 18 2690-2702.

14. Lee JH, Park EJ, Kim OS, Kim HY, Joe EH, Jou I. Double-stranded RNA-activated protein kinase is required for the LPS-induced activation of STAT1 inflammatory signaling in rat brain glial cells. Glia 2005; 50: 66-79.

15. Balachandran S, Kim CN, Yeh WC, Mak TW, Bhalla K, Barber GN. Activation of the dsRNA-dependent protein kinase PKR, induces apoptosis through FADD-mediated death signaling. EMBO J 1998; 17: 6888-6902.

16. Saelens $X$, Kalai M, Vandenabeele P. Translation inhibition in apoptosis: caspasedependent PKR activation and elF2-alpha phosphorylation. J Biol Chem 2001; 276 41620-41628.

17. Saelens X, Festjens N, Parthoens E, Vanoverberghe I, Kalai M, van Kuppeveld F et al. Protein synthesis persists during necrotic cell death. J Cell Biol 2005; 168: 545-551.

18. Vanden Berghe T, Kalai M, Denecker G, Meeus A, Saelens X, Vandenabeele P. Necrosis is associated with IL-6 production but apoptosis is not. Cell Signal 2005: 328-335.

19. Meylan E, Burns K, Hofmann K, Blancheteau V, Martinon F, Kelliher M et al. RIP1 is an essential mediator of Toll-like receptor 3-induced NF-kappa B activation. Nat Immunol 2004; 5: 503-507.

20. Kaiser WJ, Offermann MK. Apoptosis induced by the toll-like receptor adaptor TRIF is dependent on its receptor interacting protein homotypic interaction motif. J Immunol 2005 174: 4942-4952.

21. Holler N, Zaru R, Micheau O, Thome M, Attinger A, Valitutti S et al. Fas triggers an alternative, caspase-8-independent cell death pathway using the kinase RIP as effector molecule. Nat Immunol 2000; 1: 489-495.

22. Vanden Berghe T, Kalai M, van Loo G, Declercq W, Vandenabeele P. Disruption of HSP90 function reverts tumor necrosis factor-induced necrosis to apoptosis. J Biol Chem 2003 278: $5622-5629$.

23. Vanden Berghe T, van Loo G, Saelens X, Van Gurp M, Brouckaert G, Kalai M et al Differential signaling to apoptotic and necrotic cell death by Fas-associated death domain protein FADD. J Biol Chem 2004; 279: 7925-7933.

24. Gabel F, Wang D, Madern D, Sadler A, Dayie K, Daryoush MZ et al. Dynamic flexibility of double-stranded RNA activated PKR in solution. J Mol Biol 2006; 359: 610-623.

25. Jiang Z, Zamanian-Daryoush M, Nie H, Silva AM, Williams BR, Li X. Poly(I-C)-induced Tolllike receptor 3 (TLR3)-mediated activation of NFkappa B and MAP kinase is through an interleukin-1 receptor-associated kinase (IRAK)-independent pathway employing the signaling components TLR3-TRAF6-TAK1-TAB2-PKR. J Biol Chem 2003; 278 16713-16719.

26. Takada Y, Ichikawa H, Pataer A, Swisher S, Aggarwal BB. Genetic deletion of PKR abrogates TNF-induced activation of IkappaBalpha kinase JNK, Akt and cell proliferation but potentiates p44/p42 MAPK and p38 MAPK activation. Oncogene 2006; Advance online publication 21 August 2006

27. Lamkanfi M, D'Hondt K, Vande Walle L, van Gurp M, Denecker G, Demeulemeester J et al. A novel caspase-2 complex containing TRAF2 and RIP1. J Biol Chem 2005; 280 6923-6932.

28. Martinon F, Holler N, Richard C, Tschopp J. Activation of a pro-apoptotic amplification loop through inhibition of NF-kappaB-dependent survival signals by caspase-mediated inactivation of RIP. FEBS Lett 2000; 468: 134-136.

29. Vattem KM, Staschke KA, Zhu S, Wek RC. Inhibitory sequences in the N-terminus of the double-stranded-RNA-dependent protein kinase PKR, are important for regulating phosphorylation of eukaryotic initiation factor 2alpha (elF2alpha). Eur J Biochem 2001 268: 1143-1153.

30. Gelev V, Aktas H, Marintchev A, Ito T, Frueh D, Hemond M et al. Mapping of the autoinhibitory interactions of protein kinase $\mathrm{R}$ by nuclear magnetic resonance. J Mol Biol 2006 364: 352-363.

31. Nanduri S, Carpick BW, Yang Y, Williams BR, Qin J. Structure of the double-stranded RNA-binding domain of the protein kinase PKR reveals the molecular basis of its dsRNAmediated activation. EMBO J 1998; 17: 5458-5465. 
32. Clarke PA, Mathews MB. Interactions between the double-stranded RNA binding motif and RNA: definition of the binding site for the interferon-induced protein kinase DAI (PKR) on adenovirus VA RNA. RNA 1995; 1: 7-20.

33. Vyas J, Elia A, Clemens MJ. Inhibition of the protein kinase PKR by the internal ribosome entry site of hepatitis C virus genomic RNA. RNA 2003; 9: 858-870.

34. Lee TH, Shank J, Cusson N, Kelliher MA. The kinase activity of Rip1 is not required for tumor necrosis factor-alpha-induced lkappaB kinase or p38 MAP kinase activation or for the ubiquitination of Rip1 by Traf2. J Biol Chem 2004; 279: 33185-33191.

35. Bonnet MC, Weil R, Dam E, Hovanessian AG, Meurs EF. PKR stimulates NF-kappaB irrespective of its kinase function by interacting with the IkappaB kinase complex. Mol Cell Biol 2000; 20: 4532-4542.
36. Gil J, Garcia MA, Gomez-Puertas P, Guerra S, Rullas J, Nakano H et al. TRAF family proteins link PKR with NF-kappa B activation. Mol Cell Biol 2004; 24: 4502-4512.

37. Brouckaert G, Kalai M, Krysko DV, Saelens X, Vercammen D, Ndlovu M et al. Phagocytosis of necrotic cells by macrophages is phosphatidylserine dependent and does not induce inflammatory cytokine production. Mol Biol Cell 2004; 15: 1089-1100.

38. Pimentel-Muinos FX, Seed B. Regulated commitment of TNF receptor signaling: a molecular switch for death or activation. Immunity 1999; 11: 783-793.

39. Kawahara A, Ohsawa Y, Matsumura H, Uchiyama Y, Nagata S. Caspase-independent cell killing by Fas-associated protein with death domain. J Cell Biol 1998; 143: 1353-1360.

40. O'Mahoney JV, Adams TE. Optimization of experimental variables influencing reporter gene expression in hepatoma cells following calcium phosphate transfection. DNA Cell Biol 1994; 13: 1227-1232. 